\title{
Исследование сорбционных свойств природных монтмориллонитовых глин разных месторождений для очистки воды от ионов свинца (II)
}

\author{
Везенцев А.И., Перистая Л.Ф., Нгуен Фук Као, \\ Перистый В.А., Копылова Е.В. \\ Белгородский государственный национальный исследовательский университет \\ НИУ «БелГУ»,Белгород
}

Поступила в редакцию 27.09.2017 г.

\begin{abstract}
Представлены результаты исследования сорбционных характеристик природных глин месторождения «Поляна», проявления «Нелидовка» Белгородской области (Россия) и месторождения «Там Бо» (Вьетнам). Изучена кинетика процесса сорбции. Исследован гранулометрический состав глины месторождения «Поляна» и изучено его влияние на сорбционную способность. Установлено, что сорбция ионов $\mathrm{Pb}$ (II) на глинах подчиняется модели мономолекулярной адсорбции Ленгмюра. Глина месторождения «Поляна» является наиболее эффективным сорбентом среди указанных глин.

Ключевые слова: сорбция, очистка воды, монтмориллонитовые глины, кинетика и изотермы сорбции, гранулометрический состав.
\end{abstract}

\section{Research of sorption properties of natural montmorillonitovy clays of different fields for water purification from ions of lead (II)}

\author{
Vezentsev A.I., Peristaya L.F., Nguyen Fuk Kao, \\ Peristiy V.A., Kopylova E.V. \\ Belgorod state national research university NIU «BelSU», Belgorod
}

\begin{abstract}
The results of investigation of sorption characteristic of natural montmorillonite-type clay from the field «Polyna», occurrence «Nelidovka», Belgorod region (Russia) and the field Tam Bo (Vietnam) are presented. Kinetics process of the lead (II) ions sorbtion by Polyana clay was studed in the different arrangements: different mass balance of sorbate to sorbent and different initial concentration of the lead (II) ions (5 $\left.\mathrm{mg} / \mathrm{dm}^{3} ; 120 \mathrm{mg} / \mathrm{dm}^{3}\right)$. Maximum value of the average velocity is $7.9 \mathrm{mg} /\left(\mathrm{dm}^{3} \cdot \mathrm{min}\right)$. It was established that the sorbtion balance both at small and high concentration (mentioned above) come up into the 1.5 hour. The adsorbtion of lead (II) ions on the clays samples concerned has been found to take place mainly in the first 15 minutes. Grain-size composition of the clay occurrence «Polyana» in the dry condition or suspension was researched by laser analyzer with particle size LS13320. Distribution curves of entitys Polyana clays were shown by sizes for fractions like 29-67 $\mu \mathrm{m}, 67-200 \mu \mathrm{m}, 200-500 \mu \mathrm{m}$. Dispersiveness of clay in the water slurry higher than in the dry clay. Mean size in the first particle is drops by a factor of 1.14 , in the second particle is drops by a factor of 2.85 , in the biggest (third) particle is drops by a factor of 9.2. Grain-size composition influence was researched and established dependence of it on the sorption capacity with lead (II) ions. As the average size of the particles decreases more than threefold (from $360 \mu \mathrm{m}$ to $113 \mu \mathrm{m}$ ) the sorption capacity increases more than twofold (from $6.35 \mathrm{mg} / \mathrm{g}$ to $13.99 \mathrm{mg} / \mathrm{g}$ ). Further decrease of the particles size does not affect the sorption capacity. The adsorption of lead (II) ions on the sorbents involved is found to fit in with Langmuir monomolecular adsorption model in the range of initial concentrations from 80 to 440 $\mathrm{mg} / \mathrm{dm}^{3}$. Parametric variable of Langmuir equation for clays different deposit and for the different particulate
\end{abstract}


of Polyana clay: value of limitary adsorbtion $(\mathrm{mg} / \mathrm{g})$ and sorbtion balance constants $\left(\mathrm{dm}^{3} / \mathrm{mg}\right)$. The clay from «Polyna» demonstrated the maximal efficiency of purification of aqueous solution from lead (II) ions $(99.8 \%)$.

Keywords: sorption, water purification, montmorillonite clays, kinetics and isotherms of sorption, granulometric composition.

\section{Введение}

Весьма распространенными и опасными загрязнителями биосферы являются тяжелые металлы, к которым относятся более 40 химических элементов с относительными атомными массами выше 50. Загрязнение биосферы, и в частности гидросферы, является одной из важнейших экологических проблем. К числу тяжелых металлов относится и свинец. Он поступает из природных и антропогенных источников во все компоненты биосферы: атмосферу, природные воды и почву [1-3].

Попадая в организм человека с вдыхаемым воздухом, водой или пищей, свинец вызывает ряд отрицательных последствий для здоровья. Он поражает периферическую и центральную нервную систему, способствует развитию гипертонии, уменьшает скорость образования эритроцитов в костном мозге, блокирует синтез гемоглобина, вызывает (особенно у детей) ослабление умственных способностей, интенсифицирует кариес. Токсическое действие свинца связано с его способностью замещать кальций в костях и нервных волокнах. Свинец депонируется в основном в скелете в форме труднорастворимого фосфата $\mathrm{Pb}_{3}\left(\mathrm{PO}_{4}\right)_{2}$. Он способен к аккмулированию, медленно выводится из организма [4].

Одним из физико-химических методов очистки воды от ионов тяжелых металлов является сорбция. Преимуществами сорбционного метода очистки воды являются: высокая эффективность (от 80 до 99 \%); возможность очистки сточных вод, содержащих несколько веществ; рекуперация этих веществ. В последние годы проводятся исследования, направленные на очистку воды и почвы от соединений тяжелых металлов с использованием не только традиционных, хорошо известных сорбентов, таких как активные угли, но и доступных природных материалов - минеральных алюмосиликатных адсорбентов (глины, цеолитсодержащие породы и т.д.) [5-10].

Комплексный анализ сорбентов для выявления их практической пригодности для очистки воды включает исследование кинетики процесса и определение_сорбционной емкости. Важной характеристикой процесса адсорбции являются уравнения изотермы адсорбции. Наиболее часто адсорбция тяжелых металлов описывается изотермами Ленгмюра и Фрейндлиха. Первая является более универсальной, так как применима для более широкой области концентраций.

Целью настоящей работы является исследование сорбционных свойств природных монтмориллонитовых глин для очистки воды от ионов свинца (II).

\section{Эксперимент}

В качестве сорбентов использовали природные монтмориллонитовые глины месторождения «Поляна» и проявления «Нелидовка» Белгородской области (Россия) и месторождения «Там Бо» провинции Лам Донг (Вьетнам). Вещественный (химический, минералогический) состав данных глин указан в работах [11-13]. Природные глины предварительно высушили в сушильном шкафу при температуре $105^{\circ} \mathrm{C}$ до постоянной массы. Затем глины измельчали в диссольвере до порошкообразного состояния и просеивали через сито с диаметром ячеек 200 мкм. 
Для изучения влияния размера частиц глины на ее сорбционные свойства измельченную Полянскую глину просеивали через систему сит и собирали три фракции с размером частиц 29-67 мкм, 67-200 мкм и 200-500 мкм, соответственно.

В качестве сорбата использовали растворы ионов $\mathrm{Pb}^{2+}$, приготовленные из соли $\mathrm{Pb}\left(\mathrm{NO}_{3}\right)_{2}$ квалификации ч.д.а. Исходная концентрация ионов $\mathrm{Pb}^{2+}$ находилась в диапазоне 80-440 мг/дм ${ }^{3}$. Равновесную концентрацию растворов ионов $\mathrm{Pb}^{2+}$ определяли на спектрофотометре Specord 50 с помощью реакции комплексообразования ионов $\mathrm{Pb}^{2+}$ с сульфарсазеном по ГОСТ 18293-72.

Для исследования кинетики процесса сорбции в первом эксперименте готовили модельный раствор $\mathrm{Pb}\left(\mathrm{NO}_{3}\right)_{2}$ квалификации ч.д.а. с концентрацией ионов $\mathrm{Pb}^{2+}$ 5 мг/дм ${ }^{3}$. В каждую из семи пронумерованных конических колб емкостью $100 \mathrm{~cm}^{3}$ наливали $50 \mathrm{~cm}^{3}$ модельного раствора. Одновременно во все колбы добавляли 1 г исследуемой глины с размером частиц менее 200 мкм. Содержимое перемешивали в течение 1 минуты. Далее эксперимент проводили в статических условиях при температуре $20^{\circ} \mathrm{C}$. Продолжительность сорбции составляла 15, 30, 45, 60, 75, 90, 105 мин., соответственно. По истечению указанного времени содержимое всех колб перемешивали и центрифугировали. Центрифугат использовали для фотометрического определения концентрации ионов $\mathrm{Pb}^{2+}$ после адсорбции. По указанной методике исследовали кинетику сорбции с иной массой сорбента, соответственно 3 г и 5 г. Во второй серии экспериментов аналогично повторяли все опыты с другой концентрацией

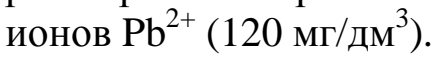

\section{Обсуждение результатов}

Кинетика поглощения ионов свинца (II) экспериментальными сорбентами. На рисунке 1 представлены кинетические кривые сорбции ионов свинца (II) на Полянской глине с размером частиц менее 200 мкм.

В первом эксперименте (рис. 1.а.), массовое соотношение сорбата к сорбенту соответственно составляло $2.5 \cdot 10^{-4}: 1 ; 8.3 \cdot 10^{-5}: 1$ и 5.0.10 $0^{-5}: 1$. Анализ кинетических кривых показывает, что во всех трех опытах (с разными массами сорбентов), поглощение ионов свинца практически происходит за первые 15 минут, а далее концентрация этих ионов уменьшается незначительно и через 75-90 минут достигается сорбционное равновесие. Например, при использовании 1 г сорбента уже за первые 15 минут концентрация снижается с 5 до 0.27 мг/дм ${ }^{3}$, то есть в 18 раз. При дальнейшем увеличении времени сорбции концентрация ионов свинца (II) изменяется незначительно в пределах погрешности определения. Эффективность очистки воды составляет $94.6 \%$. Увеличение массы сорбента сильнее снижает концентрацию ионов свинца в растворе. Эффективность очистки при использовании 3 и 5 г глины составляет 95.4 и $97.4 \%$, соответственно.

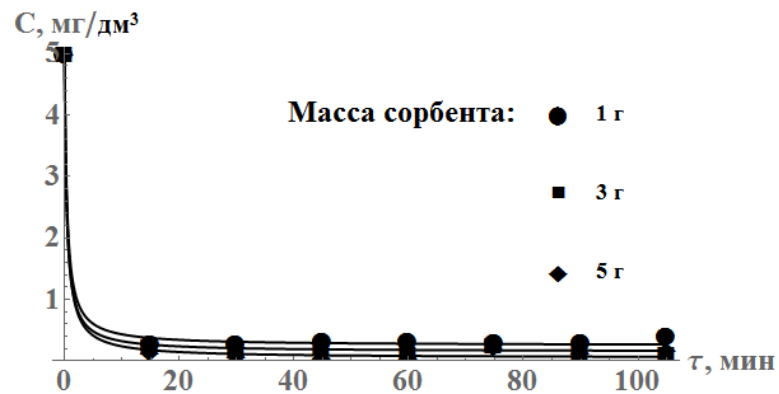

a

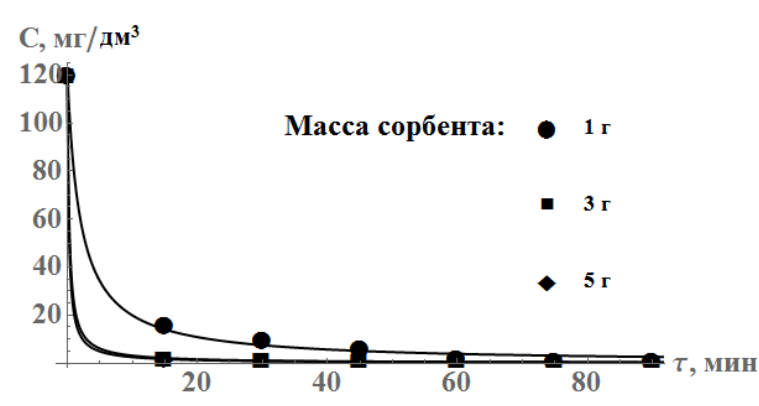

6

Рис. 1. Кинетические кривые сорбции ионов свинца (II) Полянской глиной: a) $\mathrm{C}_{\mathrm{o}}=5 \mathrm{мг} /$ дм $^{3}$; б) $\mathrm{C}_{\mathrm{o}}=120 \mathrm{мг} /$ дм $^{3}$ 
Во второй серии экспериментов (рис. 1.б.), массовое соотношение сорбата к сорбенту составляло $6.0 \cdot 10^{-3}: 1 ; 2.0 \cdot 10^{-3}: 1$; и $1.2 \cdot 10^{-3}: 1$, соответственно. При использовании 1 г сорбента, адсорбция происходит медленнее, чем при использовании большей массы сорбента (3 и 5 г). За первые 15 минут концентрация ионов свинца (II) снижается с 120 до 15.7 мг/дм ${ }^{3}$ (в 7.64 раза), а после 75 минут - до 0.60 мг/дм ${ }^{3}$, а затем перестает изменяться. С увеличением массы сорбента до 3 г эффективность очистки значительно повышается. За первые 15 минут сорбент снижает концентрацию ионов свинца (II) с 120 до 1.73 мг/дм ${ }^{3}$, т.е. в 69 раз. Концентрация ионов свинца (II) продолжает снижаться до 0.40 мг/дм ${ }^{3}$ после 60 минут, а затем перестает изменяться. При использовании большей массы глины эффективность сорбции незначительно изменяется: концентрация ионов свинца (II) в растворе после 15 минут и 60 минут составляет 1.52 и 0.42 мг/дм ${ }^{3}$, соответственно. Эффективность очистки водного раствора использованной глиной массой 1,3 и 5г после 90 минут составляет 99.5; 99.7; и $99.8 \%$, соответственно.

В таблице 1 показано увеличение скорости сорбции с уменьшением массового соотношения сорбата к сорбенту (с увеличением массы сорбента).

Таблица 1. Средняя скорость сорбции ионов свинца (II) на Полянской глине за первые 15 минут

\begin{tabular}{|c|c|c|c|c|}
\hline \multirow{2}{*}{ № } & \multirow{2}{*}{$\mathrm{C}_{\mathrm{o}}, \mathrm{мг} /$ дм$^{3}$} & \multicolumn{3}{|c|}{$\mathrm{V}_{\text {сред. }}, \mathrm{MГ} /\left(\right.$ дм$\left.^{3} \cdot \mathrm{Mин}\right)$} \\
\hline & & $1 \Gamma$ & $3 \Gamma$ & $5 \Gamma$ \\
\hline 1 & 5 & 0.31 & 0.32 & 0.33 \\
\hline 2 & 120 & 6.95 & 7.88 & 7.90 \\
\hline
\end{tabular}

Таким образом, установлено, что 90 минут - достаточное время для достижения сорбционного равновесия, как при малых, так и высоких концентрациях ионов свинца (II).

Гранулометрический состав сухой глины и ее водной суспензии. На рисунке 2 представлены кривые распределения частиц Полянской глины по размерам в сухом виде и в суспензии. Для исследованных фракций глины в сухом виде, диаметр большинства частиц находится в области 0.5-100 мкм, 30-250 мкм и 100-1000 мкм, соответственно. Сравнительный анализ кривых показывает, что при контактировании с водой глина подвергается дальнейшему диспергированию на более мелкие частицы. В водной суспензии степень дисперности глины увеличивается по сравнению с твердой глиной. Для первой фракции (29-67 мкм) средний размер частиц уменьшается в 1.14 раза, для второй фракции (67-200 мкм) - в 285 раза, для последней фракции с более крупными частицами (200-500 мкм) - в 9.2 раза (табл. 2.).

Таблица 2. Статистические параметры распределения частиц Полянской глины

\begin{tabular}{|c|c|c|c|}
\hline \multirow{2}{*}{$\begin{array}{c}\text { Фракция с } \\
\text { размером час- } \\
\text { тиц, мкм }\end{array}$} & \multirow{2}{*}{ Состояние } & \multicolumn{2}{|c|}{ Параметр } \\
\cline { 3 - 4 } & & Средний размер, мкм & Стандарт. отклонение, мкм \\
\hline \multirow{2}{*}{$29-67$} & Сухая & 20.40 & 18.82 \\
\hline \multirow{2}{*}{$67-200$} & Суспензия & 17.92 & 68.24 \\
\hline \multirow{2}{*}{$200-500$} & Сухая & 113.0 & 44.51 \\
\cline { 2 - 4 } & Суспензия & 39.71 & 170.1 \\
\cline { 2 - 4 } & Сухая & 359.7 & 49.43 \\
\hline
\end{tabular}


Все кривые распределение частиц глины в суспензии показаны на рисунке 2.d. Для всех фракций характерно преобладание частиц с диаметром в области от 2 до 10 мкм. Для фракций 67-200 мкм и 200-500 мкм дополнительно преобладают частицы с диаметром от 30 до 100 мкм, а для фракции 29-67 мкм - от 15 до 60 мкм. Средний размер частиц глины в суспензиях составляет 17.92; 39.71 и 39.08 мкм, соответственно.

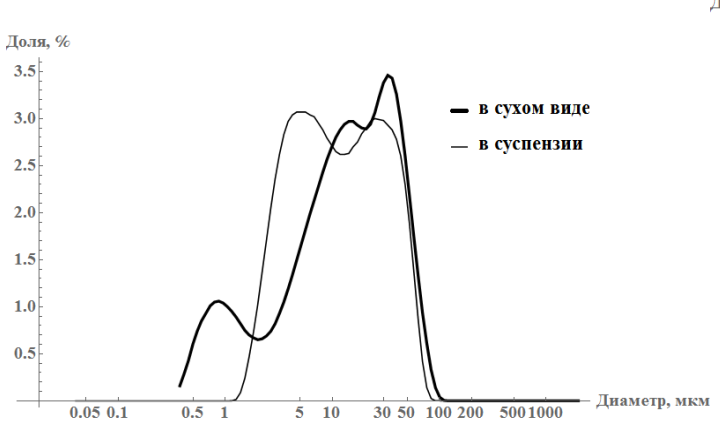

a

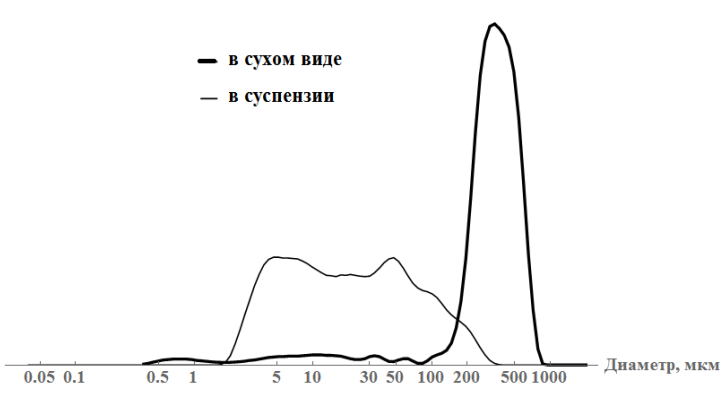

B

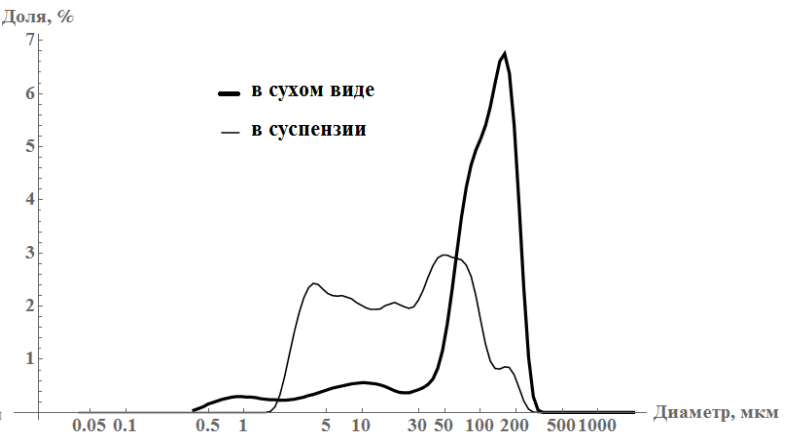

6

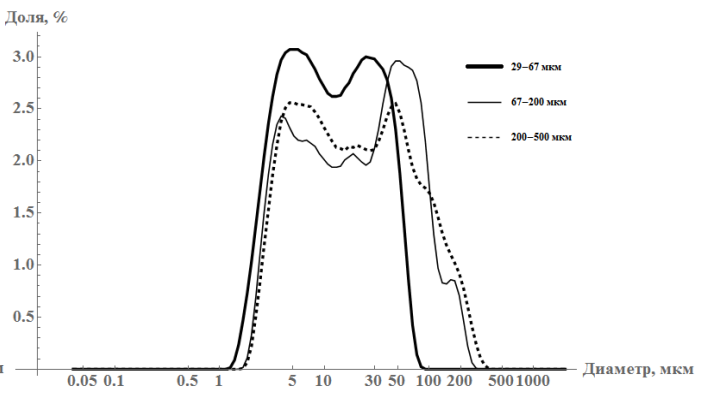

$\Gamma$

Рис. 2. Кривые распределения частиц Полянской глины по размерам:

а) 29-67 мкм; б) 67-200 мкм; в) 200-500 мкм; г) в суспензии

Результаты, представленные в табл. 3., показывают, что в водной суспензии дисперность глины выше, чем в сухом образце. В каждом из диапазонов $(<10,<25$, $<50,<75,<90 \%)$ диаметр частиц в суспензии меньше, чем в сухом порошке. Хотя исходные размеры фракций сильно различаются, их гранулометрический состав в суспензии почти совпадает, кроме первой фракции, где явно отсутствуют большие частицы изначально. Большинство частиц (около 90\%) в суспензии имеет размер менее 100 мкм.

Таблица 3. Гранулометрический состав глины

\begin{tabular}{|c|c|c|c|c|c|c|}
\hline \multirow{2}{*}{$\begin{array}{c}\text { Фракция с } \\
\text { размером } \\
\text { частиц, мкм }\end{array}$} & Состояние & $<10 \%$ & $<25 \%$ & $<50 \%$ & $<75 \%$ & $<90 \%$ \\
\cline { 3 - 7 } $29-67$ & Сухая & 1.248 & 5.556 & 14.40 & 31.31 & 47.84 \\
\cline { 2 - 7 } & Суспензия & 3.198 & 5.177 & 11.52 & 26.72 & 43.13 \\
\hline \multirow{2}{*}{$67-200$} & Сухая & 9.005 & 65.23 & 111.4 & 164.1 & 205.2 \\
\cline { 2 - 7 } & Суспензия & 3.845 & 7.084 & 22.27 & 57.83 & 96.26 \\
\hline \multirow{2}{*}{$200-500$} & Сухая & 161.8 & 259.2 & 352.3 & 473.5 & 583.2 \\
\cline { 2 - 7 } & Суспензия & 3.756 & 6.528 & 18.26 & 51.08 & 106.0 \\
\hline
\end{tabular}

Таким образом, проведенное исследование показало, что дисперность глины увеличивается при образовании ее водной суспензии. 
Изотермы сорбции ионов свинца (II) глиной разных месторождений. Важные сведения о сорбционных свойствах сорбента и характере адсорбции на нем ионов свинца можно получить из изотерм адсорбции.

На рис. 3 представлены экспериментальные изотермы адсорбции ионов свинца (II) из $50 \mathrm{~cm}^{3}$ модельного раствора нитрата свинца с исходной концентрацией ионов свинца от 80 до 440 мг/дм ${ }^{3}$ с сорбентом массой 1 г.

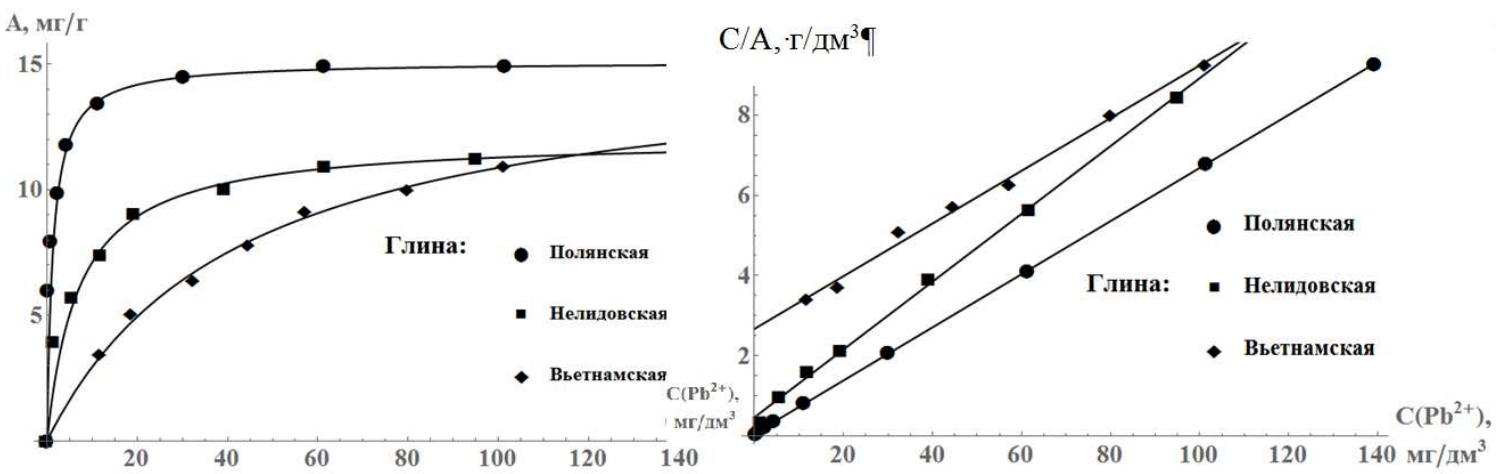

Рис. 3. Изотермы адсорбции ионов свинца (II) на глинах месторождения «Поляна», проявления «Нелидовка» и месторождения «Там Бо»

По классификации типов изотерм, предложенных в теории БЭТ, изотермы сорбции ионов свинца (II) всеми исследованными глинами с размером частиц менее 200 мкм, относятся к первому типу, характеризующему мономолекулярную Ленгмюровскую адсорбцию. Выпуклый участок изотермы указывает на наличие в сорбенте микропор. Крутизна изотермы на Полянской глине характеризует данный сорбент как ультрамикропористый, а вид изотерм сорбции на Нелидовской и Вьетнамской глине указывает на микропористый характер указанных сорбентов.

Предельное значение адсорбции на Полянской глине составляет 15.1 мг/г, оно значительно больше, чем на Нелидовской глине, для которой это значение составляет 12.1 мг/г (табл. 4). В интервале исследованных концентраций адсорбция на Вьетнамской глине не достигает максимального значения. По литературным данным, мономолекулярная адсорбция на микропористых сорбентах осуществляется в области пор с радиусом 0.5-1.6 нм [14].

Таблица 4. Параметры уравнения адсорбции Ленгмюра для глин разных месторождений

\begin{tabular}{|c|c|c|}
\hline Глина & $\mathrm{A}_{\infty}, \mathrm{Mг} / \Gamma$ & $\mathrm{K}$, дм$^{3} / \mathrm{M} \Gamma$ \\
\hline Полянская & 15.1 & 0.77 \\
\hline Нелидовская & 12.1 & 0.14 \\
\hline Вьетнамская & 15.5 & 0.023 \\
\hline
\end{tabular}

Из рисунка 4. следует, что крутизна двух изотерм с диаметром частиц 29-67 мкм и 67-200 мкм характеризует данные сорбенты как ультрамикропористые. Однако наибольшей крутизной обладает изотерма с глиной фракции 29-67 мкм. Использование глины с большим размером частиц (200-500 мкм) вызвало изменение характера изотермы: она стала менее крутой. Данный характер изотермы характеризует сорбент как микропористый. При этом значительно уменьшилась сорбционная емкость по сравнению с двумя предыдущими сорбентами с меньшими размерами частиц. Предельная адсорбция с глинами первых двух фракций составляет 13.3 мг/г и 13.99 мг/г, соответственно, а с глиной последней фракции - 6.3 мг/г, т.е. уменьшается в более, чем 2 раза (табл. 5.). 

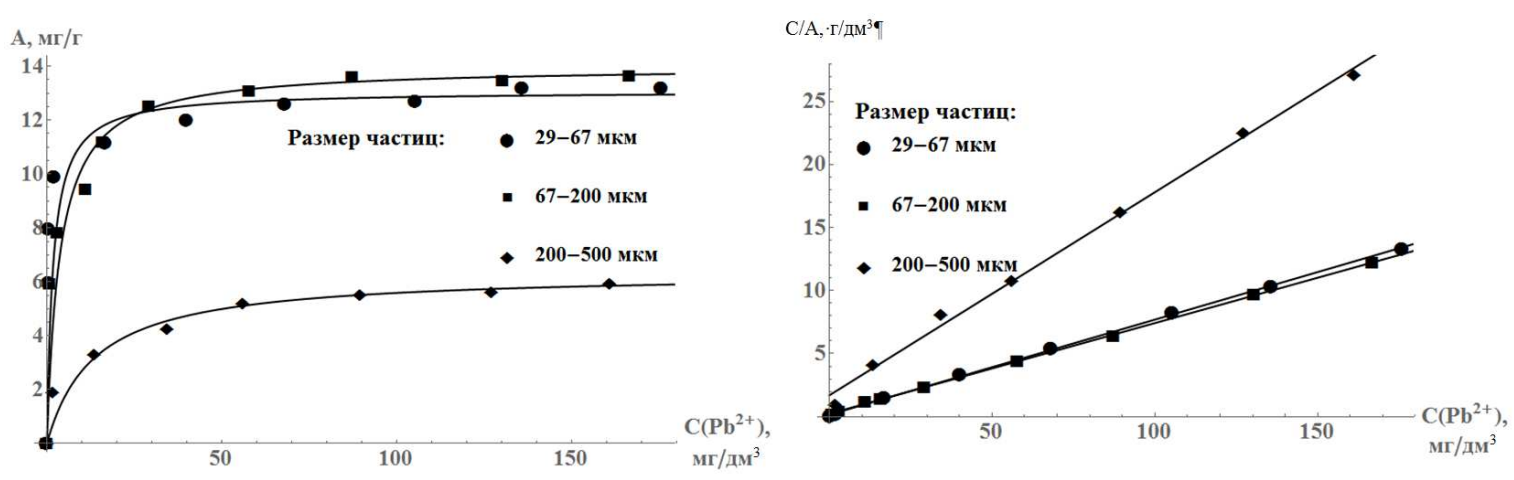

Рис. 4. Изотермы адсорбции ионов свинца (II) на Полянской глине разных фракций

Таблица 5. Параметры уравнения адсорбции Ленгмюра для Полянской глины с разными размерами частиц

\begin{tabular}{|c|c|c|}
\hline Размер частиц, мкм & $\mathrm{A}_{\infty}$, мг/Г & $\mathrm{K}$, дм$^{3} / \mathrm{Mг}$ \\
\hline $29-67$ & 13.28 & 0.33 \\
\hline $67-200$ & 13.99 & 0.27 \\
\hline $200-500$ & 6.35 & 0.074 \\
\hline
\end{tabular}

\section{Заключение}

Выявлено, что адсорбция ионов свинца (II) на исследуемых образцах глин происходит преимущественно за первые 15 минут. В водном растворе глина подвергается диспергированию на более мелкие частицы. При уменьшении среднего размера частиц сухой глины в 3 раза (от 360 мкм до 113 мкм), сорбционная емкость увеличивается в 2 раза (от 6.35 мг $\mathrm{Pb} / г$ до 13.99 мг $\mathrm{Pb} / г$ ). Дальнейшее уменьшение размера частиц не влияет на сорбционную емкость. Адсорбция ионов свница (II) на всех исследованных сорбентах в диапазоне исходной концентрации от 80 до 440 мг/дм ${ }^{3}$ соответствует модели мономолекулярной адсорбции Ленгмюра. Сорбционная емкость Полянской, Нелидовской и Вьетнамской глин составляет $15.1 ; 12.1$ и 15.5

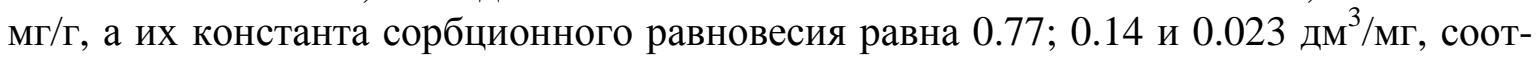
ветственно. Полянская глина является наиболее эффективным сорбентом среди использованных глин.

\section{Список литературы}

1. EEA (European Environment Agency) Progress in management of contaminated sites/ CSI 015, DK-1050. 2007. Copenhagen K, Denmark.

2. Фелленберг Г. Загрязнение природной среды. Введение в экологическую химию. М.Мир. 1997. 232 c.

3. Bowen H.J.M. Environmental Chemistry of the Elements. London, Academic Press. 1979. $333 \mathrm{p}$.

4. Плетенева Т.В., Саломатин Е.М., Сыроешкин А.В. и др. Токсикологическая химия: учебник для вузов, / под ред. Т.В. Плетеневой. М. ГЭОТАР-Медиа. 2005. 509 с.
5. Везенцев А.И., Голдовская Л.Ф., Воловичева Н.А., Королькова С.В. // Сорбиионные и хроматографические прочессы. 2008. T. 8. № 5. C 807-811.

6. Везенцев А.И., Трубицын М.А., Голдовская-Перистая Л.Ф., Воловичева Н.А. // Научные ведомости Белгородского государственного университета. Серия «Естественные науки». 2008. Т. 6. № 3 (43). С. 172-175.

7 Вигдорович В.И., Богданова Е.П., Цыганкова Л.Е., Николенко Д.В. // Сорбичинные и хроматографические проиессы. 2011. Т. 11. Вып. 6. С. 913-921.

8. Vezentsev A.I., Volovicheva N., Korolkova S., Sokolovskiy P. // International Journal of 
Applied Engineering Research (IJAER). 2015. Vol.10. № 12. pp. 31381-31388.

9. Vezentsev A.I., Goldovskaya-Peristaya L.F., Sokolovskiy P.V., Peristiy V.A. // $A d-$ vances in Environmental Biology. 2014. № 8(13). p. 13-16.

10. Vezentsev A.I., Peristaya L.F., Shamshurov A.V., Cherkasov R.A. et al. // ARPN Journal of Engineering and Applied Sciences. 2014. Vol. 9. No 11. pp. 2358-2366.

11. Везенцев А.И., Нгуен Хоай Тьяу, Соколовский П.В., Буханов В.Д. и др. // Сорбичи-

\section{References}

1. EEA (European Environment Agency)

Progress in management of contaminated sites/ CSI 015, DK-1050. 2007. Copenhagen K, Denmark.

2. Fellenberg G. Zagryaznenie prirodnoy sredyi. Vvedenie v ekologicheskuyu himiyu. M,, Mir, 1997, 232 p.

3. Bowen H.J.M. Environmental Chemistry of the Elements. London, Academic Press, 1979, $333 \mathrm{p}$.

4. Pleteneva T.V., Salomatin E.M., Syiroeshkin A.V. i dr. Toksikologicheskaya himiya: uchebnik dlya vuzov, / pod red. T.V. Pleteneva. - Moskva, GEOTAR-Media, 2005, 509 p.

5. Vezentsev A.I., Goldovskaya L.F., Volovicheva N.A., Korolkova S.V., Sorbtsionnyie $i$ khromatograficheskie protsessy, 2008, Vol. 8, No. 5, pp 807-811.

6. Vezentsev A.I., Trubitsyin M.A., Goldovskaya-Peristaya L.F., Volovicheva N.A., Nauchnyie vedomosti Belgorodskogo gosudarstvennogo universiteta. Seriya «Estestvennyie nauki», 2008, Vol. 6, No 3 (43), pp. 172-175.

7. Vigdorovich V.I., Bogdanova E.P., Tsyigankova L.E., Nikolenko D.V., Sorbtsionnyie $i$ khromatograficheskie protsessy, 2011, Vol. 11, No 6, pp. 913-921.

Везенцев Александр Иванович - д.т.н., профессор, зав. кафедрой общей химии Института инженерных технологий и естетсвенных наук Белгородского государственного национального исследовательского университета (НИУ «БелГУ»), Белгород

Перистая Лидия Федотовна - доцент кафедры общей химии Института инженерных технологий и естественных наук Белгородского государственного национального исследовательского университета (НИУ «БелГУ»), Белгород. онные и хроматографические прочессы. 2015. T. 15. № 1. С. 127-133.

12. Баранникова Е.В., Везенцев А.И. // Научные ведомости Белгородского государственного университета. Серия «Естественные науки». 2006. № 3 (23). Вып. 4. С. 52-54.

13. Милютин В.В., Везенцев А.И., Соколовский П.В., Некрасова Н.А. // Сорбционные и хроматографические проиессы. 2014. Т.14. Вып. 5. С. 879-883.

14. Везенцев А.И., Трубицын М.А., Романщак А.А. // Горный журнал. 2004. № 1. C. 51-52.

8. Vezentsev A.I., Volovicheva N., Korolkova S., Sokolovskiy P., International Journal of Applied Engineering Research (IJAER), 2015, Vol.10, No 12, pp. 31381-31388.

9. Vezentsev A.I., Goldovskaya-Peristaya L.F., Sokolovskiy P.V., Peristiy V.A. et al., $A d$ vances in Environmental Biology, 2014, No 8(13), pp. 13-16.

10. Vezentsev A.I., Peristaya L.F., Shamshurov A.V., Cherkasov R.A. et al., ARPN Journal of Engineering and Applied Sciences, 2014, Vol. 9, No 11, pp. 2358-2366.

11. Vezentsev A.I., Nguen Hoay Tyau, Sokolovskiy P.V., Buhanov V.D. et al., Sorbtsionnyie $i$ khromatograficheskie protsessy, 2015, Vol. 15, No 1, pp. 127-133.

12. Barannikova E.V., Vezentsev A.I., Nauchnyie vedomosti Belgorodskogo gosudarstvennogo universiteta. Seriya «Estestvennyie nauki», 2006, Vol. 4, No 23, pp. 52-54.

13. Milyutin V.V., Vezentsev A.I., Sokolovskiy P.V., Nekrasova N.A., Sorbtsionnyie $i$ khromatograficheskie protsessy, 2014, Vol.14, No 5, pp. 879-883.

14. Vezentsev A.I., Trubitsyin M.A., Romanschak A.A., Gornyiy zhurnal, 2004, No 1, pp 51-52.

Vezentsev Alexander I.- doctor of technical sciences, professor, head of department of the general chemistry of Institute of engineering technologies and natural sciences of the Belgorod state national research university (NIU «BelSU»), Belgorod. E-mail: vesentsev@bsu.edu.ru

Peristaya Lidia F. - assistant professor of department of the general chemistry of Institute of engineering technologies and natural sciences of the Belgorod state national research university (NIU «BelSU»), Belgorod. E-mail: peristaya@ bsu.edu.ru 
Нгуен Фук Као - магистр Института инженерных технологий и естетсвенных наук Белгородского государственного национального исследовательского университета (НИУ «БелГУ»), Белгород

Перистый Владимир Александрович - к.т.н., профессор кафедры общей химии Института инженерных технологий и естественных наук Белгородского государственного национального исследовательского университета (НИУ «БелГУ»), Белгород

Копылова Екатерина Владимировна - аспирант кафедры общей химии Института инженерных технологий и естетсвенных наук Белгородского государственного национального исследовательского университета (НИУ «БелГУ»), Белгород
Nguen Fuk Kao - magister of Institute of engineering technologies and natural sciences of the Belgorod state national research university (NIU «BelSU»), Belgorod

Peristiy Vladimir A. - candidate of technical sciences, professor of department of the general chemistry of Institute of engineering technologies and natural sciences of the Belgorod state national research university (NIU «BelSU»), Belgorod. E-mail: peristiy@bsu.edu.ru

Kopilova Ekaterina V. - postgraduate student of department of the general chemistry of Institute of engineering technologies and natural sciences of the

Belgorod state national research university (NIU

«BelSU»), Belgorod. E-mail: 040204@mail.ru 